\title{
High Field Flux Pinning and the Upper Critical Field of Nb-Ti Superconductors
}

\author{
Michael T. Naus, Robert W. Heussner, Alexander A. Squitieri and David C. Larbalestier \\ Applied Superconductivity Center, University of Wisconsin, Madison, WI 53706
}

\begin{abstract}
Nb}-\mathrm{Ti}$ wires of different composition and metallurgical state have been studied near the upper critical field

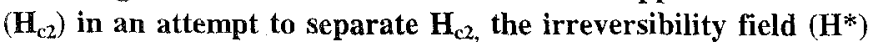
and the resistively measured transition field $\left(\mathbf{H}_{\mathrm{r}}\right)$. For optimized multifilamentary $\mathrm{Nb}-47 \mathrm{wt}$. \% $\mathrm{Ti}$ wire, we find that $\mathrm{H}^{*}=10.2 \mathrm{~T}$, $H_{\mathrm{c} 2}=10.8 \mathrm{~T}$ and $\mathrm{H}_{\mathrm{r}}=11.8 \mathrm{~T}$ at $4.2 \mathrm{~K}$. The transitions were studied by extended electric field vs. current density curves, magnetization and small current transport measurements. We found a strong correlation between magnetization, bulk flux pinning $\left(\mathbf{F}_{p}\right)$ extrapolation and extended $\mathbf{E}-J$ curves for the value of $\mathrm{H}^{*}$, all giving $\mathrm{H}^{*}=10.2 \mathrm{~T}$. We have also shown that the maximum in $\mathrm{H}_{\mathrm{r}}$ occurs for $\mathrm{Nb}-44 \mathrm{wt}$. \% $\mathrm{Ti}$.
\end{abstract}

\section{INTRODUCTION}

The demand for ever increasing fields in superconducting magnets has forced a re-examination of the high field characteristics of $\mathrm{Nb}-\mathrm{Ti}$ superconductors. Present optimization of conventionally processed $\mathrm{Nb}-47.5 \mathrm{wt} \% \mathrm{Ti}$ wire maximizes the critical current density $\left(\mathrm{J}_{\mathrm{c}}\right)$ at $4.2 \mathrm{~K}$ and 5 to $7 \mathrm{~T}$, far below the upper critical field $\left(\mathrm{H}_{\mathrm{c} 2}\right)$ and the irreversibility field $\left(\mathrm{H}^{*}\right)$ of this alloy. $\mathrm{J}_{\mathrm{c}}$ is optimized by a maximization of the bulk flux pinning force $\left(\mathrm{F}_{\mathrm{p}}\right)$, but as one goes to higher fields, $F_{p}$ quickly decreases. As shown in Figure 1 , there are crossovers in the $J_{c}(H)$ characteristics for wires of different compositions at very high fields. The question then becomes whether $\mathrm{H}_{c 2}, \mathrm{H}^{*}$ or the flux pinning microstructure plays the most important role in determining $\mathrm{J}_{\mathrm{c}}$ at fields approaching $\mathrm{H}_{\mathrm{c} 2}$

In conventional $\mathrm{Nb}-\mathrm{Ti}$ wire, $\alpha-\mathrm{Ti}$ precipitates formed during heat treatment are drawn into 1 to $2 \mathrm{~nm}$ thick ribbons which act as the primary flux pinning defects. It has been customary to examine the flux pinning properties of low temperature superconductors (LTS) by scaling the pinning force to what is generally (but wrongly) called the upper critical field. In high temperature superconductors (HTS), it is more common to scale to $\mathrm{H}^{*}$ because $\mathrm{H}^{*}<<\mathrm{H}_{c 2}$. Since $\mathrm{H}^{*} \sim 0.95 \mathrm{H}_{\mathrm{c} 2}$ for LTS, this distinction has had little practical importance until now. However, recent experimental results of Heussner et al. [1] show that $\mathrm{H}^{*}-\mathrm{H}_{\mathrm{c} 2}$ can become as large as $1.4 \mathrm{~T}$ in artificial-pinning-center (APC) $\mathrm{Nb}$-Ti wires.

The understanding of $\mathrm{H}^{*}$ and $\mathrm{H}_{\mathrm{C} 2}$ is complicated, however, by the various definitions used. For many years the standard experimental definition of $\mathrm{H}_{\mathrm{c} 2}$ was obtained by extrapolating the bulk pinning force versus applied field curve linearly to zero. This yields values of $\mathrm{H}_{\mathrm{c} 2} \approx 10.2 \mathrm{~T}$ for $\mathrm{Nb}-47.5 \mathrm{wt}$. $\% \mathrm{Ti}$. However, based on experience with HTS materials, we would now expect that this extrapolation should give $\mathrm{H}^{*}$, rather than

Manuscript received August 27, 1996.

This work is supported by the U.S. Department of Energy under grants from the Division of High Energy Physics and Fermilab.

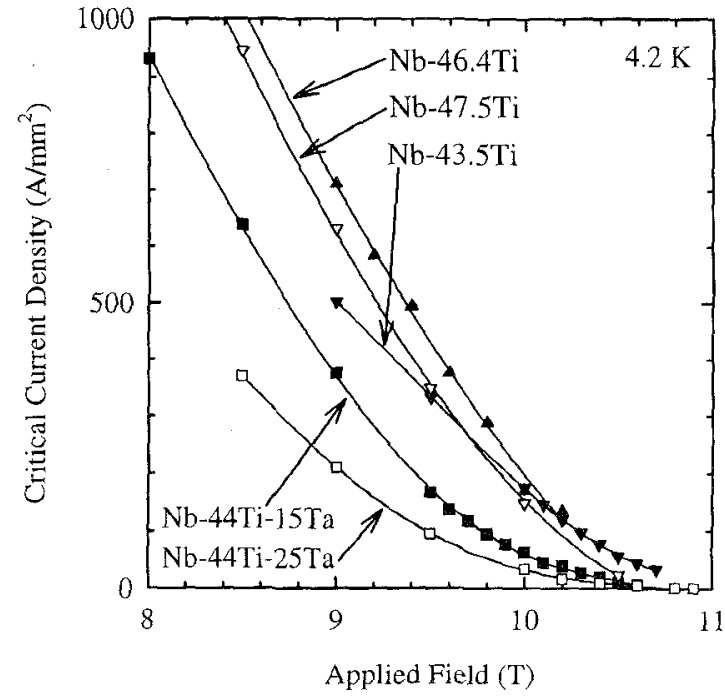

Fig. 1. High field critical current density of various $\mathrm{Nb}-\mathrm{Ti}$ and $\mathrm{Nb}-\mathrm{Ti}-\mathrm{Ta}$ alloys optimized for $5 \mathrm{~T}$. Nb-47.5wt.\% Ti, which has the highest $J_{\mathrm{c}}$ at $5 \mathrm{~T}$, is nearly $100 \mathrm{~A} / \mathrm{mm}^{2}$ below $\mathrm{Nb}-46.4 \mathrm{wt}$. \% Ti at high fields.

$\mathrm{H}_{\mathrm{c} 2}$.

An alternative method for defining $\mathrm{H}_{\mathrm{c} 2}$ uses small current resistive measurements, yielding a quantity called $H_{r}$. Previous resistive measurements [2],[3],[4] show a transition above $11.5 \mathrm{~T}$ in $\mathrm{Nb}-47.5 \mathrm{wt} . \% \mathrm{Ti}$. In contrast to transport measurements, magnetization measurements on optimized wires suggest $\mathrm{H}_{\mathrm{c} 2}$ lies at $10.7 \mathrm{~T}$ [1], between the low current resistive transition at $11.8 \mathrm{~T}$ and the onset of irreversibility, $\mathrm{H}^{*}$, (determined by hysteresis loop closure) at $10.2 \mathrm{~T}$.

The substantial disagreements between transport and magnetization techniques, and the lack of an independent check of $\mathrm{H}^{*}$, lead us to re-examine the definition of $\mathrm{H}^{*}$ and $\mathrm{H}_{c 2}$ as a foundation for better understanding how to optimize the very high field $\mathrm{J}_{\mathrm{c}}$ of $\mathrm{Nb}-\mathrm{Ti}$ alloys.

\section{EXPERIMENTAL PROCEDURE}

Magnetization measurements were made on one 61 filament $\mathrm{Nb}-47.5 \mathrm{wt} . \% \mathrm{Ti}$ composite, using 3 wires having different strains $\left(\varepsilon_{\mathrm{f}}\right)$ after 3 heat treatments of 80 hours at

TABLE I

SAMPLE CHARACTERISTICS

\begin{tabular}{cccc}
\hline $\begin{array}{c}\text { Wire } \\
\text { Diameter } \\
(\mathrm{mm})\end{array}$ & $\begin{array}{c}\text { Filament } \\
\text { Diameter } \\
(\mu \mathrm{m})\end{array}$ & $\begin{array}{c}\text { Post HT } \\
\text { Strain } \\
\left(\varepsilon_{\mathrm{f}}\right)\end{array}$ & $\begin{array}{c}\text { VSM Sample Volume } \\
\left(\mathrm{m}^{3}\right)\end{array}$ \\
\hline 3.27 & 287 & 0.0 & $1.5 \times 10^{-9}$ \\
0.643 & 55.6 & 3.25 & $0.8 \times 10^{-9}$ \\
0.254 & 22.3 & 5.11 & $1.0 \times 10^{-9}$ \\
\hline
\end{tabular}


$420^{\circ} \mathrm{C}$ (Table I). Measurements were made on extracted filaments in a vibrating sample magnetometer (VSM) at 4.2 $\mathrm{K}$. Previous magnetization tests [5] indicated that the optimized wire $\left(\varepsilon_{\mathrm{f}}=5.11\right)$ required a length of at least $44 \mathrm{~mm}$ for the $J_{c}$ curves derived from magnetization data to correspond with transport measurements well below $\mathrm{H}^{*}$. We used the filament length-to-diameter ratio $(2,000)$ of this sample to dictate the length of the sample from the wire with $\varepsilon_{\mathrm{f}}=3.25$. The $\varepsilon_{\mathrm{f}}=0.0$ sample had an aspect ratio of only 81 due to the limited length available. However, this short length does not compromise the data in the reversible regime. Filaments were wound with a radius of curvature of $-1.5 \mathrm{~mm}$ with the axis perpendicular to the applied magnetic field. Samples were tested at various magnetic field ramp rates ranging from 0.003 to $0.023 \mathrm{~T} / \mathrm{s}$.

High sensitivity transport measurements were also made on $\varepsilon_{\mathrm{f}}=3.25$ and $\varepsilon_{\mathrm{f}}=5.11$ wires at $4.2 \mathrm{~K}$. The copper cladding from the middle section of each wire was etched off to avoid current sharing effects, and the wires were mounted on G10 mandrels $35 \mathrm{~mm}$ in diameter, such that the wire axis was perpendicular to the applied field. Voltage taps were placed just outside the etched region, approximately $33 \mathrm{~cm}$ apart, and voltage was measured with a Keithley 1801 nanovolt preamp in conjunction with a Keithley 2001 multimeter. Samples were tested at magnetic fields ranging from $9.8 \mathrm{~T}$ to $10.8 \mathrm{~T}$ in $0.1 \mathrm{~T}$ steps. The pressure in the liquid helium bath space was monitored during testing as a temperature control at field.

Transport $\mathrm{J}_{\mathrm{c}}(4.2 \mathrm{~K})$ measurements were made on the $\varepsilon_{\mathrm{f}}=5.11$ wire which was soldered to a stainless steel barrel with the wire axis perpendicular to the applied field.

Arc-melted alloys ranging from $\mathrm{Nb}-30 \mathrm{wt} . \% \mathrm{Ti}$ to $\mathrm{Nb}$ $58 \mathrm{wt} . \% \mathrm{Ti}$ in $2 \mathrm{wt} . \% \mathrm{Ti}$ increments were specially prepared. They were extensively homogenized prior to drawing and were not given any $\alpha-\mathrm{Ti}$ precipitation heat treatment. However, they do have residual cold work strain in the condition used for the upper critical field measurements $\left(\mathrm{H}_{\mathrm{r}}\right)$. Samples were prepared and mounted as above with resistive measurements taken at 5 current densities ranging from 0.4 to $125 \mathrm{~mA} / \mathrm{mm}^{2}$.

\section{RESULTS}

Magnetization measurements show hysteresis loop closure $\left(\mathrm{H}^{*}\right)$ near $10.2 \mathrm{~T}$ for all samples tested (Table II). The field at closure had only a very small dependence on ramp rate - an

TABLE II

RESULTS ON MULTIFILAMENTARY Nb-47.5WT\%Ti WIRE

\begin{tabular}{cccccc}
\hline$\varepsilon_{\mathrm{f}}$ & Measurement & $\mathrm{H}^{*}(\mathrm{~T})$ & $\mathrm{H}_{\mathrm{c} 2}(\mathrm{~T})$ & $\mathrm{H}_{?}(\mathrm{~T})$ & $\mathrm{H}_{\mathrm{r}}(\mathrm{T})$ \\
\hline 0.00 & Magnetization & 10.3 & 10.8 & 11.4 & - \\
3.25 & Magnetization & 10.2 & 10.8 & 11.5 & - \\
& Extended E-J & 10.2 & - & - & - \\
5.11 & Magnetization & 10.2 & 10.8 & 11.5 & - \\
& F $_{\mathrm{p}}$ Extrapolation & 10.2 & - & - & - \\
& Extended E-J & 10.2 & - & - & - \\
& Resistive & - & - & - & 11.8 \\
\hline $\mathrm{a}$ & Resistive & - & - & - & 11.5 \\
\hline
\end{tabular}

a Single-phase monofilament order of magnitude increase in ramp rate making only $\sim 0.1 \mathrm{~T}$ increase in $\mathrm{H}^{*}$. We chose the slowest ramp rate available $(0.003 \mathrm{~T} / \mathrm{s})$ to generate the magnetization loops presented here. Figure 2 shows the magnetization curve of the wire with $\varepsilon_{\mathrm{f}}=3.25$.

Above $\mathrm{H}^{*}$, a significant slope change can be seen at $10.8 \pm$ $0.1 \mathrm{~T}$, suggesting that this marks the principal $\mathrm{H}_{\mathrm{c} 2}$ transition of the wire. As listed in Table II, magnetization measurements of the two-phase wires with $\varepsilon_{\mathrm{f}}=0,3.25$ and 5.11 showed that all had $\mathrm{H}_{\mathrm{c} 2}=10.8 \mathrm{~T}$. Close examination of the reversible portion of the curve in Figure 2 shows a slight curvature above $10.8 \mathrm{~T}$, suggesting that minority superconducting components exist above the main $\mathrm{H}_{\mathrm{c} 2}$ transition. Since these wires are highly heterogeneous (containing $\sim 20$ vol.\% of $\alpha-\mathrm{Ti}$ flux pinning nanostructure), this is not surprising. This upper transition was more dramatic in other samples. For example, Figure 3 shows the region between 10.8 and $12 \mathrm{~T}$ for the $\varepsilon_{\mathrm{f}}=0$ sample where the precipitates are 50 to $200 \mathrm{~nm}$ ellipsoids, making the microstructure more coarse and heterogeneous than for $\varepsilon_{\mathrm{f}}=3.25$ and $\varepsilon_{\mathrm{f}}=5.11$. In this case, a second slope change occurs at $11.4 \pm 0.1 \mathrm{~T}$.

A method to evaluate $\mathrm{H}^{*}$ often used in high temperature superconductors (HTS) is to analyze the electric field versus current density (E-J) characteristics plotted in log-log space [6]. Figure 4 shows the extended E-J data for the $\varepsilon_{\mathrm{f}}=5.11$ sample. Each curve represents a different magnetic field ranging from 9.8 to $10.6 \mathrm{~T}$ in $0.1 \mathrm{~T}$ steps. For HTS, $\mathrm{H}^{*}$ is identified as the field at which the E-J curvature changes sign. This can be defined by plotting the curvature of each line (i.e. the coefficient of the second order term of a quadratic fit to the curves). This method of evaluation, however, did not work for our samples, as the curvature varied widely at fields below the $\mathrm{H}^{*}$ derived from the magnetization. We instead fitted the curves to first order polynomials and plotted the

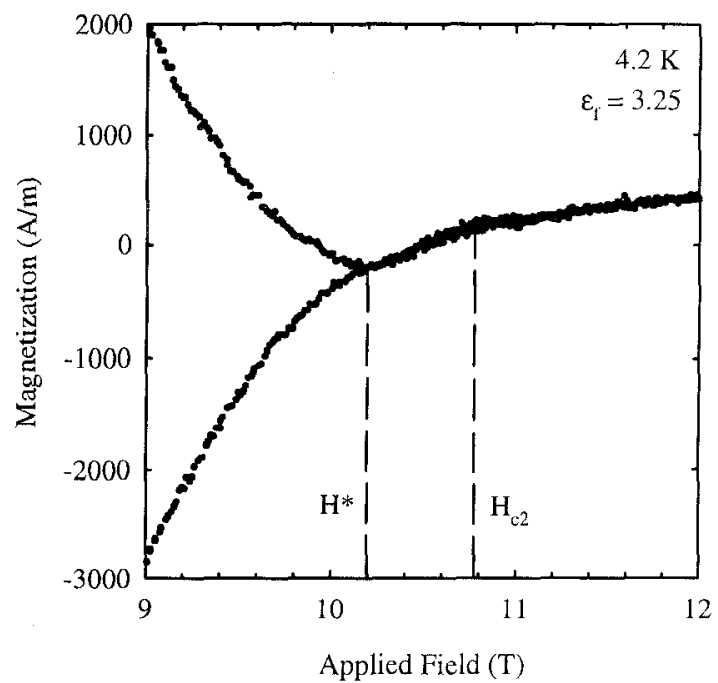

Fig. 2. Magnetization curve of the $\varepsilon_{f}=3.25$ sample at a ramp rate of 0.003 $\mathrm{T} / \mathrm{s}$. $\mathrm{H}^{*}=10.2 \mathrm{~T}$ as defined by loop closure and $\mathrm{H}_{\mathrm{c} 2}$ is the slope change at $10.8 \mathrm{~T}$. 


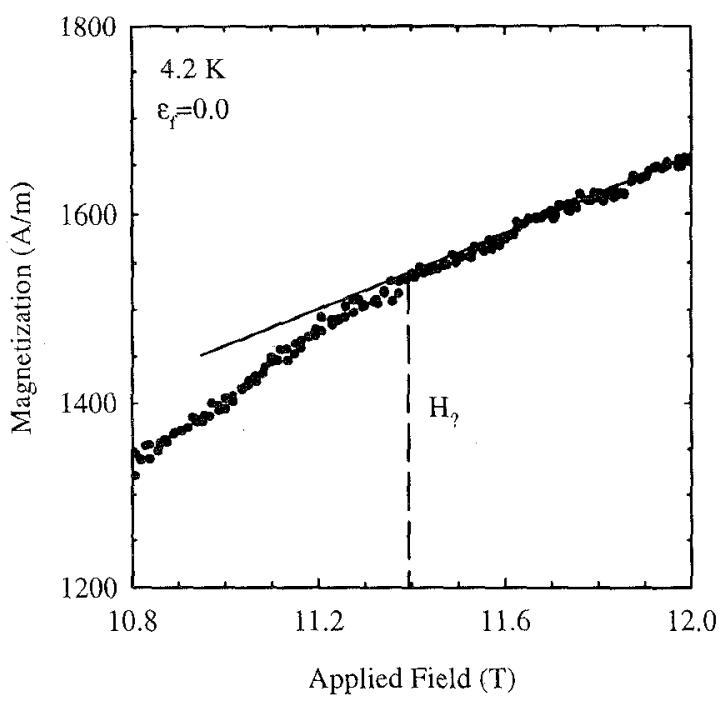

Fig. 3. Magnetization of the $\varepsilon_{\mathrm{f}}=0.0$ sample showing the second change of slope (called $\mathrm{H}_{?}$ ) at a field above $11 \mathrm{~T}$.

linear correlation coefficient ( $\mathrm{r}$ ) as a function of field, taking the maximum in $\mathrm{r}$ to be $\mathrm{H}^{*}$. This method yielded $\mathrm{H}^{*}=10.2 \mathrm{~T}$ for the optimized wire shown in Figure 4 , in excellent agreement with $\mathrm{H}^{*}$ derived from magnetization.

The bulk flux pinning force curve $\left(\mathbf{F}_{\mathbf{p}}=\mathbf{J}_{\mathbf{e}} \times \mathbf{B}\right)$ of the $\varepsilon_{\mathrm{f}}=5.11$ wire is shown in Figure 5. Linearly extrapolating $\mathrm{F}_{\mathrm{p}}$ to zero gives an $\mathrm{H}^{*}=10.2 \mathrm{~T}$. This is in excellent agreement with the $\mathrm{H}^{*}$ derived from both magnetization and $\mathrm{E}-\mathrm{J}$ measurements.

Figure 6 shows the resistive $H_{r}$ measurements on singlephase $\mathrm{Nb}-\mathrm{Ti}$ wires as a function of composition, together with the measurement on the two-phase optimized wire $\left(\varepsilon_{\mathrm{f}}=5.11\right)$. $\mathrm{H}_{\mathrm{r}}$ was determined by the intersection of the linear extrapolation of the resistive transition through the baseline voltage for each current density tested (Figure 7 (inset)). The lowest current measurements were used to define the $H_{r}$ values given in Figure 6 . In contrast to the single-phase wire, the transition of the optimized wire not only occurs at a higher field, but is also much broader.

\section{DISCUSSION}

$\mathrm{H}^{*}$ seems to be well defined by $\mathrm{F}_{\mathrm{p}}$ extrapolation, closure of the hysteresis loop and linearity in extended E-J curves. The $\mathrm{H}^{*}$ for all three methods and wire strains was $\sim 10.2 \pm 0.1 \mathrm{~T}$. Historically, the extrapolation to $\mathrm{F}_{\mathrm{p}}=0$ was taken as $\mathrm{H}_{\mathrm{c} 2}$, but our data shows that it is actually $\mathrm{H}^{*}$. It was expected that, as the pinning center size decreased, and the pin number density increased, $\mathrm{H}^{*}$ would increase, due to stronger flux pinning. However, $H^{*}$ for the two-phase wire was insensitive to pinning center size. An opposite effect is seen in APC wires with $\mathrm{Nb}$ pins in which $\mathrm{H}^{*}$ is seen to decrease with pinning center size [1].

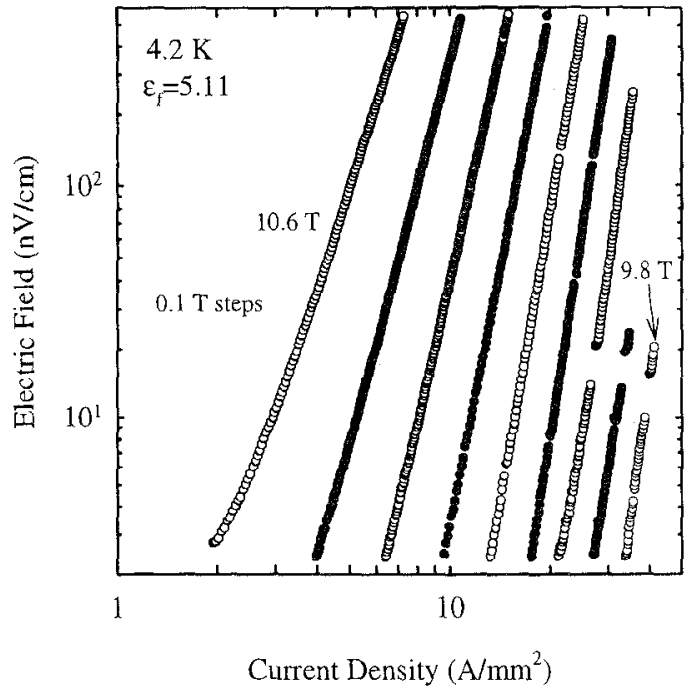

Fig. 4. Extended E-J plots of the $\varepsilon_{\mathrm{f}}=5.11$, Nb-47.5wt.\% Ti optimized wire, $\mathrm{H}^{*}$, defined as the field with maximum linearity in log space, lies between 10.2 and $10.3 \mathrm{~T}$.

The upper critical field varied widely between the different measurement methods. In magnetization measurements, the major change in slope typically associated with $\mathrm{H}_{\mathrm{c} 2}$ occurred at $10.8 \mathrm{~T}$ for the two-phase $\mathrm{Nb}-47.5 \mathrm{wt} . \% \mathrm{Ti}$ wire. However, resistive upper critical field measurements $\left(\mathrm{H}_{\mathrm{r}}\right)$ at very low current densities on the same sample gave an $\mathrm{H}_{\mathrm{r}}=11.8 \mathrm{~T}$.

An explanation for the larger resistive $\mathrm{H}_{\mathrm{r}}$ measurement over the $\mathrm{H}_{\mathrm{c} 2}$ from magnetization could be an increase in $\mathrm{H}_{\mathrm{c} 2}$ along small pathways. The upper critical field follows the equation

$$
\mu_{0} \mathrm{H}_{\mathrm{c} 2}=3.1 \times 10^{3} \gamma \rho_{\mathrm{N}} \mathrm{T}_{\mathrm{c}}
$$

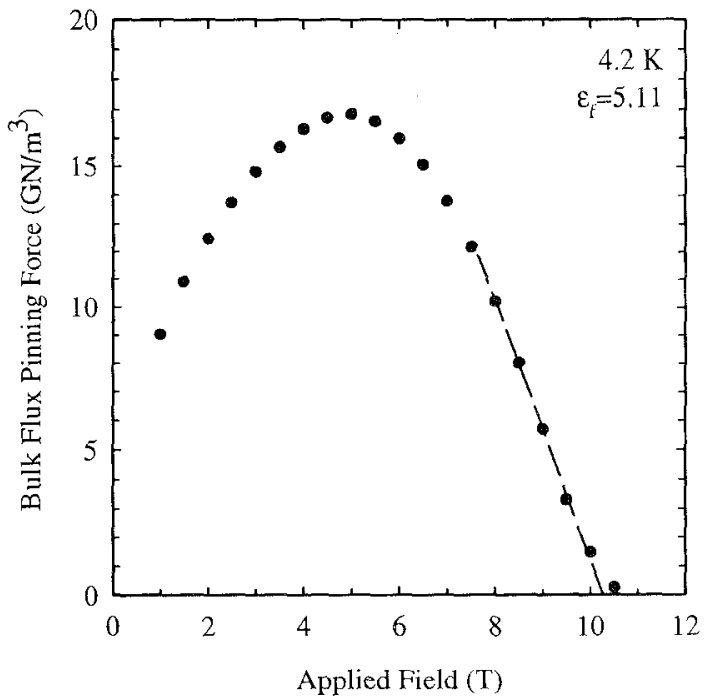

Fig. 5. Bulk flux pinning force as a function of the applied field for the $\varepsilon_{f}=5.11$ wire. A linear extrapolation of $F_{p}$ to zero gives $H^{*}=10.2 \mathrm{~T}$, in good agreement with $\mathrm{H}^{*}$ from magnetization and $\mathrm{E}-\mathrm{J}$ measurements. 


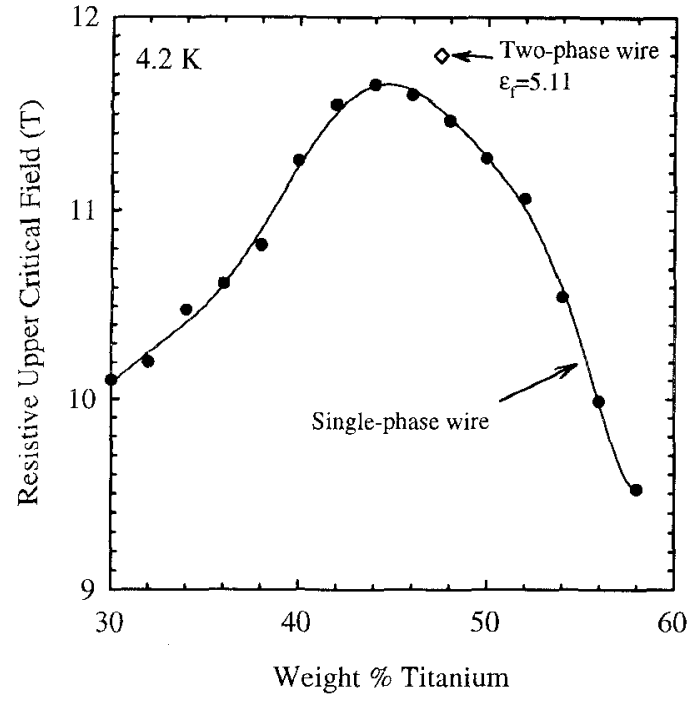

Fig. 6. $\mathrm{H}_{\mathrm{r}}$ measurement of single-phase and of the optimized Nb-47.5wt $\% \mathrm{Ti}$ wires.

where $\gamma$ is the electronic specific heat coefficient, $\rho_{\mathrm{N}}$ is the normal state resistivity and $T_{c}$ is the critical temperature. In the heterogeneous microstructure of the two-phase wire, it is conceivable that there exist pathways that have an increased $\rho_{\mathrm{N}}$ and $T_{\mathrm{c}}$ (both of which are functions of composition) such that $\mathrm{H}_{\mathrm{c} 2}$ is increased. These pathways have a large influence in transport measurements as these measurements need only a small volume of enhanced $\mathrm{H}_{\mathrm{c} 2}$ pathways for the small currents supplied. Reversible magnetization measurements, however, are more of a volumetric average of the material undergoing a $\mathrm{H}_{c 2}$ transition.

The two slope changes seen in the magnetization measurements can be ascribed to compositional variations within the wire. This would imply that the majority of the superconducting matrix has an $\mathrm{H}_{\mathrm{c} 2}$ transition at $10.8 \mathrm{~T}$ (where the larger slope change occurs). The smaller transition, at $\mathrm{H}_{2}=11.4 \mathrm{~T}$, may then represent the composition with the highest $\mathrm{H}_{\mathrm{c} 2}$ within the wire.

It is also possible that the higher transition is a manifestation of an $\mathrm{H}_{\mathrm{c} 3}$ transition on the sides of the filament which are parallel to the applied field. However, $\mathrm{H}_{\mathrm{c} 3}=1.69 \mathrm{H}_{\mathrm{c} 2}$ for parallel field and our upper field transition occurs at $\mathrm{H}_{?}=1.06 \mathrm{H}_{\mathrm{c} 2}$. Subsequent measurements with $\mathrm{Cu}$ present, which would suppress any $\mathrm{H}_{\mathrm{c} 3}$ transition, will be able to resolve this issue.

\section{CONCLUSIONS}

$\mathrm{H}^{*}$ and $\mathrm{H}_{\mathrm{c} 2}$ measurements have been made on an optimized multifilamentary $\mathrm{Nb}-47.5 \mathrm{wt}$.\% Ti wire via magnetization and transport measurements at $4.2 \mathrm{~K}$. There is excellent agreement between extrapolation of the $\mathrm{F}_{\mathrm{p}}$ curve,

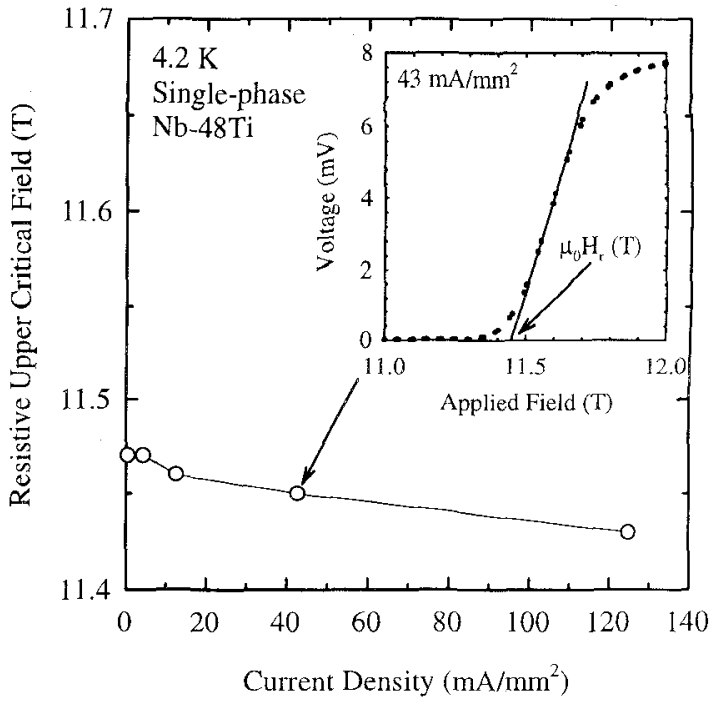

Fig. 7. $\mathrm{H}_{\mathrm{r}}$ measurement of single-phase $\mathrm{Nb}-48 \mathrm{wt} \% \mathrm{Ti}$ as a function of current density. The linear extrapolation of the resistive transition to zero determines $\mathrm{H}_{\mathrm{r}}$ at that current density (inset). The extension to zero current defines $\mathrm{H}_{\Gamma}$.

magnetization measurement and extended E-J curves that $\mathrm{H}^{*}=10.2 \mathrm{~T} \pm 0.1 \mathrm{~T}$. The resistive upper critical field, $\mathrm{H}_{\mathrm{r}}$, of $11.8 \mathrm{~T}$ for the optimized wire is higher than both that from single-phase, homogenous wires $(11.5 \mathrm{~T})$ and from magnetization $(10.8 \mathrm{~T})$ on the same wire. This may be the result of an increase in $\mathrm{H}_{\mathrm{c} 2}$ along small pathways in the twophase microstructure that are absent in the single-phase wire. It is then conceivable that $10.8 \mathrm{~T}$ (from magnetization) represents the transition of only the majority superconducting component within the wire.

\section{ACKNOWLEDGEMENTS}

We would like to thank Aaron Lindner and Patrick McKenna for their experimental assistance.

[1] R.W. Heussner, C. Bormio Nunes, P.J. Lee, P.D. Jablonski and D.C. Larbalestier, "Properties of niobium-titanium superconducting wires with $\mathrm{Nb}$ artificial pinning centers," J. Appl. Phys. 80, 3, 1640-46 (1996).

[2] D.G. Hawksworth, Ph.D. Thesis, University of Wisconsin - Madison, (1981).

[3] M. Suenaga and K.M. Ralls, "Some Superconducting Properties of TiNb-Ta Alloys," J. Appl. Phys. 40, 11, 4457-63 (1969).

[4] H. Hillman and K.J. Best, "New Measurements of Critical Data of Optimized NbTi Superconductors," IEEE Trans. Mag. 13, 5, 1568-70 (1977).

[5] C. Bormio Nunes, unpublished data.

[6] R.H. Koch, V. Foglietti, W.J. Gallagher, G. Koren, A. Gupta and M.P.A. Fisher, "Experimental Evidence for Vortex-Glass Superconductivity in Y-Ba-Cu-O," Phys. Rev. Lett. 63, 14, 1511-14 (1989). 